\title{
Pobreza e desigualdades educacionais: uma análise com base nos Planos Nacionais de Educação e nos Planos Plurianuais Federais*
}

\section{Poverty and educational inequalities: an analysis based on the National Education Plans and the Multiannual Federal Plans}

\author{
Adir Valdemar Garcia** \\ Jaime Hillesheim**
}

\begin{abstract}
RESUMO
As desigualdades educacionais constituem grave problema na sociedade brasileira e estão relacionadas à estrutura socioeconômica do país, sendo a pobreza sua expressão mais explícita. Por sua natureza, os instrumentos de planejamento e gestão do Estado apresentam as propostas para a administração do país, dentre elas as que visam enfrentar as desigualdades sociais e educacionais e a pobreza. No artigo, os autores problematizam como esses temas são apresentados nos Planos Nacionais de Educação (PNEs), de 2001-2010 e 2014-2024, e quais proposições são vislumbradas para o seu enfrentamento. Numa análise comparativa, procuram traçar relação entre as proposições consignadas nos PNEs e as constantes nos três Planos Plurianuais (PPAs) federais no período de 2004 a 2015. O PNE é o instrumento que define as diretrizes e as metas para a gestão e financiamento da educação. O PPA tem a função de organizar e viabilizar a ação pública por meio de diretrizes, objetivos e metas que devem balizar a elaboração das Leis Orça-
\end{abstract}

DOI: $10.1590 / 0104-4060.51386$

* Pesquisa financiada com recursos do Fundo Nacional de Desenvolvimento da Educação (FNDE) a partir da Iniciativa Educação, Pobreza e Desigualdade Social, Secretaria de Educação Continuada, Alfabetização, Diversidade e Inclusão (Secadi/MEC).

** Universidade Federal de Santa Catarina. Florianópolis, Santa Catarina, Brasil. Campus Reitor João David Ferreira Lima, s/n - Trindade. CEP: 88040-900. E-mail: adir.vg@ufsc.br; jaimehil@yahoo.com.br. 
mentárias Anuais (LOA). A pesquisa em desenvolvimento evidencia que, nos períodos aludidos, os PNEs e os PPAs caracterizaram-se por formalmente apresentar propostas de ampliação das políticas sociais voltadas para o combate à pobreza e à diminuição das desigualdades sociais e educacionais, a partir de diversos programas sociais, especialmente do Programa Bolsa Família. Os temas, conceitos e ações encontrados nos instrumentos de gestão analisados são problematizados à luz de referenciais da teoria social crítica.

Palavras-chave: Desigualdades educacionais. Pobreza. Plano Nacional de Educação. Plano Plurianual.

\begin{abstract}
Educational inequalities are a serious problem of Brazilian society and are related to the socio-economic structure of the country, poverty being its most apparent expression. By its nature, the State's instruments of planning and management present proposals to the administration of the country, those aimed at addressing social and educational inequalities and poverty among them. In this article, the authors problematize how these topics are presented in the National Plan of Education (Planos Nacionais de Educação - PNE) 2001-2010 and 2014-2024 and which propositions are considered as possible solutions. In a comparative analysis, the authors seek to trace the relationship between the proposals contained in the PNE and those in the three Federal Pluriannual Plans (Planos Plurianuais - PPAs) from the period of 2004 to 2015. The PNE is the instrument that sets the guidelines for management and funding of education. The PPA, in turn, aims to organize and facilitate public action through guidelines, objectives and goals that should guide the preparation of the Annual Budget Law (Leis Orçamentárias Anuais LOA). Research shows that, in the periods mentioned, the PNE and the PPA were characterized by formally presenting proposals for the expansion of the social policies to fight poverty and reduce social and educational inequalities, based on various social programs, especially Brazil's antipoverty, cash-transfer Bolsa Família program. The themes, concepts and actions found in the analyzed management tools are problematized in light of critical social theory.
\end{abstract}

Keywords: Educational inequalities. Poverty. National Plan of Education. Federal Pluriannual Plans. 


\section{Introdução}

Este artigo é resultado parcial de uma pesquisa mais ampla sobre a relação entre educação, pobreza e desigualdade social, cujas fontes são os Planos de Educação, os Planos Plurianuais (PPAs), as Diretrizes Curriculares, nas três esferas de governo, e os Projetos Políticos Pedagógicos de escolas de municípios de Santa Catarina. O objetivo da pesquisa é analisar as concepções de pobreza e desigualdade social e as proposições de enfrentamento dessas realidades apresentadas pelos governos, verificando se e como essas concepções e proposições materializaram-se no cotidiano escolar no período de 2003 a 2015.

Neste artigo, problematizaremos, de modo específico, a questão da pobreza e das desigualdades educacionais com base nos documentos federais, em particular, nos PNEs e nos PPAs. As desigualdades educacionais constituem grave problema da sociedade brasileira e estão relacionadas à estrutura socioeconômica do país, sendo a pobreza sua expressão mais explícita.

Considerando a natureza dos documentos pesquisados, a metodologia de exposição tomará os PNEs como condutores das análises, tendo em vista que indicam as diretrizes e metas para a gestão e financiamento da educação definidas nacionalmente e que devem ser consideradas na elaboração dos Planos de Educação e PPAs em todos os níveis de governo.

O PPA é um instrumento previsto no art. 165 da Constituição de 1988. Esse documento deve contemplar as políticas públicas do governo para um período de quatro anos, tendo a função de organizar e de viabilizar a ação pública por meio de diretrizes, objetivos e metas que devem balizar a elaboração das Leis Orçamentárias Anuais (LOA). Ele apresenta a visão de futuro para o país e permite, também, que a sociedade possa ter um maior controle sobre as ações governamentais. Os PPAs são compostos pela lei que os institui e por um conjunto de anexos. Foram analisados, com relação aos PPAs, os anexos que tratam do diagnóstico da realidade e que apresentam as estratégias, as diretrizes, os objetivos e as metas governamentais.

Neste artigo, serão analisados os PNEs de 2001-2010 e 2014-2024 (BRASIL, 2001, 2014), bem como os três PPAs federais (BRASIL, 2004, 2008, 2012) relativos ao período da pesquisa (2004-2007, 2008-2011 e 2012-2015). Cabe destacar que o período definido coincide com o da administração dos governos petistas. 


\section{Pobreza e desigualdades educacionais nos PNEs e nos PPAs}

A pobreza e a desigualdade social são tratadas, nos PNEs e nos PPAs analisados, como "problemas" centrais a serem atacados, sendo a educação uma mediação fundamental para o seu enfrentamento. Os documentos não apresentam uma elaboração conceitual específica sobre tais categorias, tampouco desenvolvem quaisquer reflexões sobre os determinantes estruturais da pobreza e das desigualdades sociais (e educacionais especificamente). De modo geral, com base na distinção apresentada por Garcia (2012), considerando a tomada das linhas de pobreza e pobreza extrema, além de outros indicadores como referência, podemos entender que há um foco na dimensão econômica do fenômeno, ao mesmo tempo que a ênfase dada à necessidade de fortalecimento da cidadania assinala a sua dimensão política. A partir da conjugação dessas duas dimensões, também é possível afirmar que, tomando-se os documentos na sua totalidade, há uma caracterização da pobreza como um fenômeno multifacetado (SALAMA; DESTREMAU, 1999). Isso fica claro quando são considerados, na formulação dos documentos analisados, fatores, como local de residência, condição social e econômica, disparidades geográficas, desigualdade de gênero e etnia, estrutura e composição familiar, dificuldade de acesso aos bens culturais, desigualdades educacionais, entre outros fatores.

Por sua vez, as desigualdades educacionais, por constituírem uma expressão das desigualdades sociais, também são consideradas um importante parâmetro para a organização da política educacional. De modo geral, são referenciadas a partir do dimensionamento do número de analfabetos (absolutos e funcionais); do abandono escolar; dos índices de repetência; de anos de estudo; da qualidade do ensino, considerando as estruturas escolares e a formação dos profissionais da educação, tudo isso, relacionado aos fatores anteriormente citados.

Para dimensionar a importância que a pobreza e as desigualdades educacionais alcançam nos documentos, apresentamos alguns de seus aspectos destacados.

O enfrentamento da pobreza com a mediação da política de educação aparece nos dois PNEs analisados, mas nem sempre é possível verificar avaliações que possam revelar os avanços alcançados. No PNE 2001-2010, quando são resgatados aspectos históricos da construção da política de educação no Brasil, é mencionado que, ao longo do tempo, a educação foi considerada como "[ [...] condição para o desenvolvimento do país" (BRASIL, 2001, p. 6). Ao não se identificar oposição a essa perspectiva, parece que os formuladores do PNE com ela concordam. No entanto, em todo o texto, não são feitas referências ao 
tipo de desenvolvimento proposto e defendido. É tomado como pressuposto, contudo, que o Brasil se constituía numa economia subdesenvolvida, e que tal condição impunha desafios à educação como política capaz de contribuir para a sua superação (BRASIL, 2014, p. 24). Destacamos que a ideia de subdesenvolvimento não aparece, posteriormente, nem no Plano de Desenvolvimento da Educação (PDE), nem no PNE 2014-2024.

Ainda, em ambos os PNEs analisados, constatamos que a expansão da cobertura educacional está vinculada à priorização dos segmentos mais pobres, ora concebidos como "camadas sociais mais necessitadas" ou residentes em "bolsões de pobreza existentes nas periferias", ora como "carentes" ou em "situação de vulnerabilidade social". A insuficiência de recursos para o atendimento das demandas da política de educação é tomada como um dado e aparece como justificativa para tal priorização. Entretanto, o PNE 2001-2010 traz a advertência de que a "democratização do acesso" não poderia reduzir a qualidade da educação, tampouco permitir a formulação de uma educação pobre para pobres (BRASIL, 2001).

Cabe destacar que a expansão da cobertura educacional, nos termos aludidos tanto no PNE 2001-2010 como no PNE 2014-2024, seria realizada em "regime de colaboração", o que significa dizer, efetivamente, que a consecução das proposições estaria ancorada na lógica do mercado.

À medida que a educação é vislumbrada como meio para a superação das condições de pobreza, sua articulação com outras políticas sociais, como saúde, assistência social, moradia, trabalho e emprego etc., é reforçada. Essa tentativa de integração de ações envolvendo todos os entes da federação e a sociedade civil organizada não é algo novo quando se pensa nos desenhos e no conteúdo das políticas públicas, o que indica que as estratégias adotadas, com base na intersetorialidade, não têm alcançado resultados suficientes para alterar a fragmentação e, por vezes, a duplicidade de ações, cujo produto final é a manutenção da realidade que se tenta alterar. Essa articulação também consta no PNE 2014-2024 como uma importante estratégia para o enfrentamento da pobreza. Nele destaca-se a defesa de ações que possam garantir, especialmente, o acesso e a permanência na educação de estudantes oriundos das famílias beneficiárias dos programas de transferência de renda (BRASIL, 2014).

No PNE 2001-2010, ainda ganha relevo a ideia de que o enfrentamento da pobreza exige uma política de educação que potencialize a empregabilidade dos jovens, considerando as exigências colocadas por um mercado de trabalho em constantes mudanças. Ainda que esta seja a diretriz, no documento analisado, parece haver uma tentativa de dar um tratamento "equitativo" entre uma formação de cariz técnico e àquela de caráter humanista que garanta o desenvolvimento de competências mais "gerais". De todo modo, é asseverado 
que a educação deve desenvolver as competências relacionadas ao exercício da cidadania e, ao mesmo tempo, permitir a inclusão produtiva (BRASIL, 2001). No PNE 2014-2024, a educação profissional, científica e tecnológica é apontada como uma prioridade, cuja expansão - triplicação do número de matrículas até o final do período - deverá ser viabilizada especialmente pela rede federal com a adoção de políticas afirmativas, levando em conta "[...] as peculiaridades das populações do campo, das comunidades indígenas e quilombolas e das pessoas com deficiência" (BRASIL, 2014, p. 54).

As diretrizes e metas definidas nesses PNEs, especialmente as constantes do PNE 2001-2010, ganham evidência mais operativa nos PPAs elaborados no período. Nesse sentido, verificamos que, no Anexo I - Orientação Estratégica de Governo, do PPA 2004-2007 (aprovado pela Lei $\mathrm{n}^{0}$ 10.933, de 11 de agosto de 2004), é vislumbrada uma estratégia de desenvolvimento de longo prazo, destacando a inclusão social e a desconcentração de renda, aliadas a um vigoroso crescimento do produto e do emprego como fundamentais para o processo de desenvolvimento do país. Isto fica mais evidente quando essa estratégia de longo prazo é decomposta em três megaobjetivos, quais sejam: 1) inclusão social e redução das desigualdades sociais; 2) crescimento com geração de emprego e renda, ambientalmente sustentável e redutor das desigualdades regionais; 3) promoção e expansão da cidadania e fortalecimento da democracia.

Da mesma forma que no anterior, o PPA 2008-2011 (aprovado pela Lei ${ }^{0}$ 11.653, de 7 abril de 2008) apresenta como maior desafio a aceleração do crescimento econômico com promoção da inclusão social e redução das desigualdades regionais. Esse PPA organiza as ações governamentais para o período em três eixos: 1) crescimento econômico; 2) agenda social; 3) educação de qualidade. Um elemento a destacar nesse PPA é a centralidade dada à educação. O PDE foi colocado como elemento essencial para o desenvolvimento do país, principalmente no sentido da qualificação da educação. A economia seria dinamizada pelo Programa de Aceleração do Crescimento (PAC). Dentro da agenda social, é dada atenção especial às transferências condicionadas de renda associadas ao fortalecimento da cidadania e dos direitos humanos, bem como da cultura e da segurança pública.

Nesse PPA, é reafirmada, como um dos compromissos fundamentais para o período, a construção de um Brasil onde "o crescimento econômico não esteja dissociado da distribuição de renda e do equilíbrio ambiental; a educação de crianças, jovens e adultos, a promoção da inclusão social e a redução da desigualdade estejam no topo das prioridades nacionais" (BRASIL, 2007, p. 11, grifo nosso). Esse compromisso é a indicação de que o Plano Plurianual 2008-2011 deveria continuar articulando e integrando as principais políticas públicas para o alcance dos objetivos de governo, bem como dando continuidade 
à estratégia de desenvolvimento de longo prazo apresentada no PPA 2004-2007. Nesse sentido, no documento é afirmado que, para o período 2008-2011, seria promovido o desenvolvimento com inclusão social e educação de qualidade.

O PPA 2012-2015 (aprovado pela Lei $\mathrm{n}^{\mathbf{0}} 12.593$, de 18 de janeiro de 2012) traz um balanço do período anterior, afirmando que é possível vislumbrar, para as próximas décadas, "um país que elegeu um projeto de desenvolvimento inclusivo com políticas públicas de transferência de renda, intensificação da extensão e do alcance dos programas sociais e constantes aumentos reais do salário mínimo" (BRASIL, 2011, p. 15).

No documento é destacada a importância do Estado numa crítica ao modelo neoliberal que vigorou na década de 1990, reforçando a importância de a construção do "futuro" se dar de forma conjunta com as empresas e a população. Nesse PPA, o PAC também ganha destaque. A visão de futuro alicerça-se nos seguintes valores: Soberania; Democracia; Justiça Social; Sustentabilidade; Diversidade Cultural e Identidade Nacional; Participação Social e Excelência na Gestão.

O grande desafio para o PPA 2012-2015 era dar continuidade ao padrão de desenvolvimento, aprofundando a melhoria da distribuição de renda e da riqueza, reduzindo a pobreza. É importante verificar que a avaliação feita no PPA 2012-2015 já considera os "perigos" postos pela situação internacional. No entanto, ainda se pode verificar uma grande expectativa em relação à situação "de solidez" da economia brasileira.

Novamente, um dos desafios apresentados é o reforço do modelo de consumo e produção de massa, buscando aprofundar o processo de redução das desigualdades por meio das políticas de transferência de renda, valorização do salário mínimo, expansão dos postos de trabalhos formais e inclusão produtiva. O grande desafio colocado é a erradicação da pobreza extrema. Para tanto, o Plano Brasil Sem Miséria é destacado, visto que seu objetivo é possibilitar a incorporação de um contingente ainda maior de brasileiros ao mercado interno, garantindo, também, uma forma de produção e consumo ambientalmente sustentáveis. No âmbito do plano supracitado, ganharam destaque as ações relacionadas ao Programa Nacional de Acesso ao Ensino Técnico e Emprego (Pronatec) - cursos gratuitos de qualificação profissional; ao apoio ao Microempreendedor Individual (MEI) - constituindo também estratégia de inclusão previdenciária; ao Programa Crescer - oferta de crédito para estruturação de pequenos negócios; e à Economia Solidária - formação profissional, assistência técnica e incubação de empreendimentos solidários.

No que tange às desigualdades educacionais, da análise dos PNEs selecionados, depreende-se que são compreendidas a partir da existência de disparidades na oferta de serviços educacionais, haja vista a admissão de que 
historicamente as unidades educacionais situadas em territórios ocupados pelas populações mais empobrecidas foram preteridas em relação a outras. De acordo com os termos expressos no próprio PNE 2001-2010, os “[...] indicadores apontam para a profunda desigualdade regional na oferta de oportunidades educacionais e a concentração de população analfabeta ou insuficientemente escolarizada nos bolsões de pobreza existentes no país" (BRASIL, 2001, p. 40). Ao mencionar a questão da alocação dos recursos financeiros, por exemplo, é apontada a necessidade de estabelecimento de critérios que permitam diminuir as desigualdades existentes nos sistemas educacionais no que tange à distribuição daqueles recursos (BRASIL, 2001). Nessa direção, ainda durante a vigência do PNE 2001-2010, o governo de Luiz Inácio Lula da Silva procedeu à substituição do Fundo de Manutenção e Desenvolvimento do Ensino Fundamental e de Valorização do Magistério (FUNDEF) pelo Fundo de Manutenção e Desenvolvimento da Educação Básica e de Valorização dos Profissionais da Educação (FUNDEB). Com isso, o governo garantiu o aumento do repasse dos recursos aos municípios com base em critérios objetivos, como número de matrículas, tempo de permanência dos estudantes na escola etc.

Polêmicas derivaram dessas indicações de critérios objetivos para o repasse de recursos aos entes federados. Nos debates do PNE 2014-2024, por exemplo, houve a defesa, por parte de parlamentares, de que esse repasse estivesse vinculado proporcionalmente ao desempenho das escolas no Índice de Desenvolvimento da Educação Básica (IDEB). Nessa direção, estar-se-ia admitindo a instituição de um ranking educacional, no qual as unidades escolares mais bem colocadas seriam beneficiadas com mais recursos, e as piores, consequentemente, teriam menos recursos.

Avançando em nossa análise, é importante destacar que na Lei $\mathrm{n}^{\circ}$ 13.005/2014, instituidora do PNE 2014-2024, quando da apresentação das diretrizes do plano, em seu art. $2^{\circ}$, inciso III, é mencionada a "superação das desigualdades educacionais com ênfase na promoção da cidadania e na erradicação de todas as formas de discriminação" (BRASIL, 2014, p. 32). Os avanços que daí podem ser extraídos, especialmente a ampliação da participação de segmentos populacionais historicamente alijados do acesso à política educacional em todos os níveis de formação (indígenas, quilombolas, negros etc.), acabam sendo neutralizados com a adoção de uma lógica de avaliação baseada na meritocracia e no ranqueamento.

Com vistas a diminuir as desigualdades educacionais, no mesmo plano, é prevista a universalização dos níveis educacionais compreendidos entre a educação infantil e o ensino médio, bem como a elevação das taxas de alfabetização da população com 15 anos ou mais (93,5\% do universo até 2015) e expansão da educação profissional técnica de nível médio. Fica evidenciada na 
definição dessas metas - notadamente em relação à escolarização de jovens e adultos e à educação profissional técnica - uma preocupação centrada muito mais na "certificação" do que no processo educacional que atenda efetivamente às necessidades dos trabalhadores e a formação do "cidadão", como se propõe. $\mathrm{O}$ alcance de tais metas envolve, especialmente, os jovens de famílias pobres, de modo a prepará-los precariamente para o mundo do trabalho em condições também muito precárias.

As desigualdades educacionais no âmbito da educação superior devem ser enfrentadas, segundo consta no PNE 2014-2024, por meio da ampliação de políticas inclusivas e de assistência estudantil direcionadas para os estudantes das instituições públicas, estudantes bolsistas das instituições privadas e beneficiários do Fundo de Financiamento Estudantil (FIES). Tais ações são vislumbradas como essenciais para a redução das desigualdades étnico-raciais, bem como para ampliar o acesso e a permanência, nas universidades, dos estudantes pobres oriundos das escolas públicas, afrodescendentes, indígenas, com deficiência, entre outros (BRASIL, 2014).

Para que as desigualdades educacionais apontadas nesse plano sejam enfrentadas a partir das diretrizes propostas, a ampliação dos investimentos públicos em educação pública é também prevista. O documento traz que até 2019 os investimentos em educação devam consumir 7\% do PIB do país. Até o final do decênio (2024), esse percentual deverá atingir 10\%. Nesses percentuais, estarão computados os investimentos relativos às isenções fiscais que financiam o Programa Universidade para Todos (Prouni) e o Programa Nacional de Acesso ao Ensino Técnico e Emprego (Pronatec), bem como aqueles relativos à concessão do FIES, atendendo às pressões do empresariado da educação privada. Isso porque a concepção de "público", expresso na lei instituidora do plano, foi ampliada e prevê que a política de educação pode ser implementada por meio de parcerias público-privadas, conforme se denota dos termos do art. $5^{\circ}, \S 4^{\circ}$ da Lei $n^{\circ} 13.005 / 2014$. A despeito disso, essa proposição progressiva de investimentos públicos na política de educação parece que sofrerá com os impactos da desaceleração do crescimento econômico do país, não vislumbrada em sua plena dimensão no momento da elaboração do último PNE em 2014.

As desigualdades educacionais também são referenciadas nos PPAs do período. O PPA 2004-2007, em seu Anexo I, descreve o cenário educacional, informando da sua precariedade, tanto em termos de alcance como de qualidade. Entendemos que esse cenário foi decisivo no sentido da centralidade dada à educação no PPA 2008-2011 a partir do PDE. Este prioriza a melhoria da qualidade da educação básica, o que implica, segundo consta no próprio documento, investimentos na educação profissional e na educação superior, dada a ligação entre os diferentes níveis de ensino. Para o desenvolvimento do PDE, o governo 
conclamou a mobilização social para a defesa da importância da educação. Isso levou à criação, no contexto do PPA referenciado, do Programa Compromisso Todos pela Educação.

No PPA 2008-2011, encontramos que "[...] as desigualdades educacionais entre as diversas regiões, o campo e a cidade, os diferentes segmentos de renda, bem como entre brancos e negros torna-se imprescindível para identificar os segmentos da população em desvantagem no acesso à educação de qualidade" (BRASIL, 2007, p. 74), o que confirma as diretrizes expressas no PNE 20012010, reiteradas no PNE 2014-2024. O documento informa que o Governo Federal, à época, vinha buscando romper o círculo vicioso estabelecido na relação entre vulnerabilidade social e fracasso escolar. Nesse sentido, seria necessário equalizar as condições de acesso e permanência, bem como elevar substancialmente a qualidade do ensino.

Por sua vez, o PPA 2012-2015 traz que, apesar de todos os avanços na área e no mercado de trabalho, muitos são os desafios para garantir a cidadania da juventude. É necessário investir no aumento da permanência na escola, na elevação do nível de escolaridade, na ampliação do número de matrículas no ensino superior e na educação técnica e profissional, na contenção da inserção precoce no mercado de trabalho, entre outros aspectos, reforçando a continuidade da persistência de um quadro de desigualdades educacionais no país.

\section{Proposições de enfrentamento da pobreza e das desigualdades educacionais nos PNEs e PPAs: algumas reflexões}

Considerando a análise dos PNEs e dos PPAs no que diz respeito ao tratamento dado aos temas pobreza e desigualdades educacionais, entendemos ser importante, inicialmente, destacar dois pontos que julgamos fundamentais: 1) a necessidade de estabelecimento de um "círculo virtuoso da economia" relacionado à educação e aos programas de transferência de renda; 2) o papel do Estado na consecução do modelo de desenvolvimento proposto, especialmente com relação às políticas de educação e de transferência de renda. Esses dois pontos são fundamentais para compreendermos, efetivamente, as relações que são traçadas entre pobreza e educação.

O primeiro ponto a ser analisado é a defesa de um modelo de desenvolvimento econômico baseado na ampliação do consumo interno. Esse aspecto aparece de modo explícito e enfático, especialmente, nos três PPAs analisados. Esses documentos demonstram que as proposições de enfrentamento à pobre- 
za e às desigualdades sociais e educacionais estão relacionadas diretamente à possibilidade de estabelecimento do "círculo virtuoso da economia". Ele se expressa num movimento em que a elevação da produtividade gera maiores lucros tendendo a beneficiar as famílias a partir do aumento dos rendimentos do trabalho que, por sua vez, se convertem em consumo, mobilizando as forças produtivas no sentido da expansão dos investimentos e do progresso técnico. No entanto, como verificamos no período, o acesso das famílias trabalhadoras ao consumo deu-se pela via do endividamento, com a expansão do crédito.

Para que esse círculo virtuoso se estabelecesse, os documentos indicam que não bastaria contar com o mercado de trabalho, sendo necessário o investimento em educação e em políticas de inclusão social e de redução das desigualdades, consideradas fundamentais não só para o estabelecimento da justiça social, mas também indispensáveis à operação do modelo de consumo de massa.

Considerando o conteúdo dos PNEs e a relevância dada à educação no processo de desenvolvimento do país, entendemos que ela compõe essa estratégia, afinal, um círculo virtuoso da economia representa o estabelecimento do desenvolvimento. Não sem motivo, no PNE 2001-2010, a educação é posta como condição para o desenvolvimento do país, categorizado, naquele momento, como subdesenvolvido, como posto anteriormente. Vale lembrar que a categoria subdesenvolvimento é bastante controvertida para pensar-se a condição econômica do Brasil e sua inserção no sistema capitalista mundial. Ela traz consigo uma ideia de que a pobreza vivenciada nos países de economia periférica é derivada das condições exclusivamente internas, e que sua superação implica adesão às programáticas adotadas pelas economias centrais, o que é um equívoco, segundo Frank (1973, p. 26), pois os países hoje considerados desenvolvidos "[...] nunca foram subdesenvolvidos, embora possam ter sido não-desenvolvidos".

Considerando a relação educação e pobreza, cabe destacar que a educação é apresentada, nos documentos analisados, como "política prioritária" em razão dos problemas educacionais enfrentados pelo país, bem como "política prioritária" por ser determinante no sentido de auxiliar no enfrentamento de outros "problemas sociais", a exemplo da pobreza e das desigualdades sociais em geral. O governo é incisivo ao afirmar que inclusão e desenvolvimento sustentável são inviáveis sem educação universal e de qualidade. Por isso a elevação da qualidade da educação nacional é tomada como estratégica e urgente, com o objetivo de preparar, especialmente, crianças e jovens para os desafios da vida em sociedade, para a inclusão cidadã e para a inserção no mundo do trabalho. Essa ação deveria incidir sobre todos os níveis e modalidades da educação pública. O PPA 2012-2015 mantém a educação como um dos aspectos fundamentais para a convergência do desenvolvimento econômico e social entre as regiões. 
No que tange à importância das políticas sociais, em especial, as de transferência de renda, verificamos a ocorrência de uma ampliação substancial de programas estruturados para dar conta de questões fulcrais para o país, em especial, da pobreza. O mais proeminente no período foi o Programa Bolsa Família (PBF), criado em 2003, no primeiro mandato do presidente Luiz Inácio Lula da Silva.

O PPA 2008-2011, ao tratar da agenda social, apresenta um conjunto de iniciativas, com ênfase: nas transferências condicionadas de renda associadas às ações complementares; no fortalecimento da cidadania e dos direitos humanos; na cultura; e na segurança pública. Essas iniciativas priorizam os mais vulneráveis. A agenda social também tinha por objetivo promover alternativas de emancipação para as famílias beneficiárias do PBF, integrando-as a políticas de acesso à educação, à energia, aos produtos bancários, ao trabalho e à renda, possibilitando a continuidade da redução da pobreza e da desigualdade.

O governo federal destaca no PPA 2008-2011 que a transferência de renda com condicionalidades, o aumento da renda média do trabalhador e a valorização do salário mínimo, experimentados nos últimos anos, produziram melhorias nos indicadores sociais de pobreza e desigualdade. Ao fazer referência ao PBF, o documento assevera que este tem por objetivo

contribuir para a redução da fome, da pobreza, da desigualdade e de outras formas de privação vividas pelas famílias mais excluídas, considerando três dimensões: o alívio imediato da pobreza, por meio da transferência de renda diretamente às famílias pobres e extremamente pobres; a contribuição para a redução da pobreza da geração seguinte, por meio do reforço do direito de acesso aos serviços de saúde e de educação como cumprimento das condicionalidades nestas áreas; e a articulação de ações complementares, de forma a desenvolver as capacidades das famílias beneficiárias em superar a condição de pobreza e exclusão social. (BRASIL, 2007, p. 65-66).

No PPA 2012-2015, a expansão e a melhor distribuição de rendimentos oriundos do trabalho e das transferências focalizadas aparecem como elementos fundamentais para a continuidade do processo de inclusão social. Nesse sentido, o Programa Bolsa Família e os Benefícios de Prestação Continuada e os da Previdência Social continuaram configurando importantes fontes de desconcentração de rendimentos. Ainda com relação ao PBF, o documento destaca que as condicionalidades atuam de duas formas: contribuindo para que as famílias 
tenham acesso a serviços sociais básicos e fortaleçam sua autonomia; rompendo com o ciclo intergeracional de reprodução da pobreza. O descumprimento das condicionalidades, por sua vez, pode indicar vulnerabilidade, risco social ou violação de direitos sociais das famílias. Nesse sentido, indica a necessidade de atuação prioritária das políticas sociais, envolvendo as três esferas de governo. Ainda que não possamos, aqui, ampliar a discussão a respeito, merece menção as polêmicas relativas às condicionalidades, bem como a adoção da matricialidade sociofamiliar na condução das políticas de enfrentamento da pobreza.

Esses breves registros a respeito da pretensão de estabelecimento de um círculo virtuoso na economia brasileira permitem apresentar algumas considerações. Inicialmente, é importante perceber que a forma como essa proposição é apresentada indica uma possibilidade de continuidade, ou seja, uma vez estabelecido, cabe a manutenção dos elementos que o possibilitaram. Esta é uma perspectiva claramente socialdemocrata, visto que implica uma atuação do Estado como indutor, normatizador e regulador do sistema, conforme propõe Dupas (1999). Nesse sentido, Laurell (1998) afirma que o problema das economias latino-americanas não é tanto de escassez, mas de prioridade, constituindo-se, antes de tudo, um problema político. Segundo a autora,

a exigência maior consiste na construção de um círculo virtuoso de fundamentos firmes para uma ampla base tributária, que depende da criação de empregos, do aumento dos salários e da taxação progressiva, e para uma reorientação dos subsídios aos grupos financeiros para as instituições de bem estar social. Um aumento gradual mas contínuo no gasto social não é irrealista e até contribuiria para o crescimento econômico, ao contrário do que sustenta a ortodoxia neoclássica (LAURELL, 1998, p. 202, grifo nosso).

Não podemos negar que há certos encaminhamentos na política econômica e social do período que indicam uma proximidade com o que propõem Dupas e Laurell. O Estado brasileiro, no período, garantiu uma distribuição de renda que levou, mesmo que possamos questionar a medida, milhões de brasileiros a ultrapassarem a linha de pobreza. Porém, considerando o funcionamento da ordem social do capital, o que verificamos é que o estabelecimento do círculo virtuoso proposto não se sustenta. Mesmo que medidas econômicas, a exemplo do PAC, e sociais, a exemplo da educação e daquelas voltadas para a distribuição de renda, possam ser efetivadas, a lógica da acumulação não permite esse tão esperado desenvolvimento "sustentável" e "inclusivo", redutor das desigualdades 
sociais e garantidor da cidadania, dos direitos humanos e de relações democráticas. O que a realidade nos mostra, ao contrário, é um processo de destruição, cada vez mais acentuado, dos direitos historicamente garantidos.

Considerando a perspectiva socialdemocrata, trazemos o segundo ponto importante a destacar, ou seja, o papel atribuído ao Estado em todo o processo de desenvolvimento proposto nos documentos analisados. Apesar de os documentos darem, de início, a impressão de que o que se configura é a proposição de estruturação de um Estado de Bem-Estar Social nos moldes da proposta socialdemocrata clássica, uma análise mais cuidadosa mostra que a diluição do papel do Estado está posta. Por exemplo, com relação à gestão das políticas sociais, o governo federal, no Anexo I do PPA 2004-2007, diz que, mesmo que o Estado permaneça como principal protagonista de uma política de inclusão social, seriam necessários mais esforços no sentido de somar todos os recursos - financeiros, políticos, culturais, materiais e organizacionais - disponíveis na sociedade. Segundo o governo, isso não significaria uma substituição de papéis ou delimitações de campos de ação, mas o estabelecimento de mecanismos que evitassem superposições, paralelismos e desperdícios, garantindo a complementaridade das ações do Estado e das organizações da sociedade, fossem elas mercantis ou não.

Uma tendência mercantilizante não pode ser ignorada, especialmente quando se trata da educação. Concordamos com aqueles analistas que percebem nos PNEs - e, acrescentamos, seus desdobramentos nos PPAs nos períodos correspondentes - uma evidente opção pela mercantilização da educação como estratégia para ampliar a cobertura da política e reduzir as desigualdades educacionais. Sob as orientações dos organismos internacionais, a política de educação acompanhou a dinâmica do campo econômico, sendo planejada à luz dos ajustes estruturais pretendidos e das contrarreformas do Estado brasileiro (LEHER, 2003; CURY, 2005). A política de educação fica subjugada inteiramente aos interesses produtivos, de modo que as defesas de uma "educação para a cidadania" não têm sustentação na realidade concreta, salvo se destinada a formar apenas "cidadãos-consumidores". Trata-se, pois, de um processo que atinge não apenas o ensino superior, haja vista que nos municípios brasileiros a privatização do ensino fundamental avança a passos largos e faz aumentar ainda mais as desigualdades educacionais, conforme mostram estudos recentemente realizados ${ }^{1}$.

1 Nesse sentido, ver importante estudo disponibilizado no site Observatório da Educação sobre a adoção do sistema privado de ensino no Brasil. Disponível em: $<$ http://www.observatoriodaeducacao.org.br/mapas/\#/>. Acesso em: 31 jul. 2016. 
Outro aspecto que observamos nos documentos analisados é o reforço à política de conciliação de interesses de classes levada a cabo pelos governos petistas. Na política de educação, essa perspectiva teve sua expressão mais proeminente no Plano de Metas Compromisso Todos pela Educação, instituído em 2007. Ainda que não possamos, aqui, aprofundar essa questão, merece destaque o fato de que a criação de múltiplos espaços de discussões como estratégia para aproximar forças antagônicas presentes na sociedade brasileira - como os comitês locais previstos no referido plano - contribuíram para a condução de processos caracterizados por um pluralismo sem direção social ou identidade de classe, o que reforçou o apassivamento dos trabalhadores e corroborou para a construção de uma "nova pedagogia da hegemonia" (NEVES, 2005).

\section{Considerações finais}

Os documentos analisados apresentam como característica comum a proposição de ações voltadas para o combate à pobreza e para a redução das desigualdades sociais e educacionais. No entanto, mais do que no PNE 20012010, no PNE 2014-2024 (e no PDE elaborado em 2007) e nos PPAs elaborados a partir de 2004, constata-se uma perspectiva de ampliação das políticas sociais. Ganha destaque, nesse sentido, o Programa Bolsa Família e as estratégias de articulação entre as políticas de assistência social, saúde e educação. Apesar de identificarmos iniciativas inovadoras que resultaram em importantes avanços na área social ao compararmos os governos petistas com os governos precedentes, é preciso ter presente que o sistema de produção e reprodução do capital impõe limites a qualquer política que pretenda ampliar os processos de redistribuição da riqueza, haja vista que o objetivo essencial do capital é a acumulação. Além disso, é necessário levar em conta que o Estado capitalista não pode, por sua própria razão de existência, desenvolver políticas de enfrentamento da questão social de forma duradoura, pois constitui um complexo parcial que integra o complexo mais amplo, gerador dos próprios processos que pretende combater. Nesse sentido, as proposições formuladas para o enfrentamento da pobreza e das desigualdades educacionais vislumbradas nos documentos mencionados configuram uma forma de dissimular um fato incontestável: a incontrolabilidade do sistema do capital. Em síntese, as diretrizes político-econômicas que nortearam as ações dos governos no período estudado, ainda que neguem a assunção da programática neoliberal, constituem uma variação dessa perspectiva, haja vista que seus fundamentos foram preservados. Se na aparência aquelas proposições 
aproximam-se de uma perspectiva socialdemocrata, na essência incorporam uma lógica de mercado, na qual os interesses do capital são tomados como "interesses de todos".

\section{REFERÊNCIAS}

BRASIL. Lei n 10.172, de 9 de janeiro de 2001. Plano Nacional de Educação [20012010]. Congresso Nacional. Brasília, 2001.

BRASIL. Lei no 10.933, de 11 de agosto de 2004. Plano Plurianual 2004/2007. [Anexo I - Orientação Estratégica de Governo]. Brasília: CN, 2004. Disponível em: <http:// www.planalto.gov.br/ccivil_03/_ato2004-2006/2004/lei/110.933.htm>. Acesso em: 13 ago. 2016.

BRASIL. Ministério do Planejamento, Orçamento e Gestão. Secretaria de Planejamento e Investimentos Estratégicos. Plano Plurianual 2008-2011. Brasília: MP, 2007.

BRASIL. Lei no 11.653, de 7 abril de 2008. Plano Plurianual 2008/2011. Brasília/DF, 2008. Disponível em: <http://www.planalto.gov.br/ccivil_03/_ato2007-2010/2008/lei/ 111653.htm>. Acesso em: 20 ago. 2016.

BRASIL. Ministério do Planejamento, Orçamento e Gestão. Secretaria de Planejamento e Investimentos Estratégicos. Plano Plurianual 2012-2015. Brasília: MP, 2011.

BRASIL. Lei no 12.593, de 18 de janeiro de 2012. Plano Plurianual 2012/2015. Brasília/ DF, 2012. Disponível em: <http://www.planalto.gov.br/ccivil_03/_ato2011-2014/2012/ Lei/L12593.htm>. Acesso em: 20 ago. 2016.

BRASIL. Lei no 13.005, de 25 de junho de 2014. Plano Nacional de Educação [2014-2024]. Brasília: Câmara dos Deputados, Edições Câmara, 2014. 86 p. (Série legislação; n. 125).

CURY, C. R. J. O público e o privado na história da educação brasileira: concepções e práticas educativas. In: LOMBARDI, J.C.; JACONELI, M.R.M.; SILVA. T.M. (Org.). $O$ público e o privado na história da educação brasileira: concepções e práticas educativas. Campinas: Autores Associados, 2005.

DUPAS, G. Economia global e exclusão social: pobreza, emprego, Estado e o futuro do capitalismo. 2. ed. São Paulo: Paz e Terra, 1999.

GARCIA, A. V. A pobreza humana: concepções, causas e soluções. Florianópolis: Editoria em Debate, 2012. Disponível em: <http://editoriaemdebate.ufsc.br/catalogo/a-pobreza-humana/>. Acesso em: 26 jul. 2016.

FRANK, A. G. Desenvolvimento e Subdesenvolvimento Latino-americano. In: PEREIRA, L. (Org.). Urbanização e Subdesenvolvimento. RJ: Zahar, 1973. 
LAURELL, A. C. Para um novo Estado de bem-estar na América Latina. Lua Nova, São Paulo, n. 45, p. 187-204, 1998.

LEHER, R. Reforma do Estado: o privado contra o público. Trabalho, Educação e Saúde, Rio de Janeiro, v. 1, n. 2, p. 203-228, 2003.

NEVES, L. M. W. (Org.). A nova pedagogia da hegemonia: estratégias da burguesia brasileira para educar o consenso na atualidade. São Paulo: Xamã, 2005.

SALAMA, P.; DESTREMAU, B. O tamanho da pobreza: economia política e distribuição da renda. Rio de Janeiro: Garamond, 1999.

Texto recebido em 24 de março de 2017.

Texto aprovado em 12 de abril em 2017. 
